Tema: Solidificação / Lingotamento

\title{
ANÁLISE DA INJEÇÃO DE GÁS NO DISTRIBUIDOR PARA MELHORIA NA REMOÇÃO DE INCLUSÕES*
}

\author{
Alexandre de Freitas Gomes de Mendonça ${ }^{1}$ \\ Filipe Alvarenga Araújo ${ }^{2}$ \\ Laura Oliveira Lamas ${ }^{2}$ \\ Lorena Campolina Milan Lucrécio ${ }^{2}$ \\ Roberto Parreiras Tavares ${ }^{3}$
}

\section{Resumo}

A remoção de inclusões no distribuidor de lingotamento contínuo tem sido intensamente investigada por meio de modelamentos físicos e matemáticos. Recentemente, a injeção de gás no distribuidor tem sido considerada como uma alternativa para aprimorar a remoção de inclusões. Vários trabalhos vêm sendo desenvolvidos analisando os efeitos da injeção de gás e sua interação com as inclusões. No entanto, há espaço para mais investigações envolvendo o efeito da vazão do gás, a localização do sistema de injeção de gás e as dimensões das bolhas na eficiência de remoção de inclusões. No presente trabalho, foi usado um modelo físico construído em uma escala 1:3 de um distribuidor industrial de 40 toneladas de capacidade nominal, para analisar a injeção de gás e seu efeito no padrão do fluxo de fluído e a remoção de inclusões. Os experimentos incluíram a determinação de curvas DTR e visualizações do escoamento. Os efeitos de diferentes vazões e localizações das injeções foram analisados.

Palavras-chave: Distribuidor; Injeção de gás, Modelamento físico, Inclusões.

\section{ANALYSIS OF GAS INJECTION IN TUNDISHES TO IMPROVE INCLUSION REMOVAL}

\section{Abstract}

Inclusion removal in continuous casting tundishes has been extensively investigated by means of physical and mathematical modeling. More recently, gas injection in tundishes has been considered as an alternative to improve inclusion removal. Several works have been developed analyzing the effect of gas injection and its interactions with inclusions, however, there is room for more investigations regarding the effect of gas flow rate, location of the gas injection system and bubble dimensions on the inclusion removal efficiency. In the present work, a physical model of an industrial tundish of 40 tonnes of nominal capacity, built in a 1:3 scale, was used to analyze gas injection and its effect on the fluid flow pattern and on inclusion removal. The experiments included determination of RTD curves and flow visualization. The effects of different gas, flow rates and locations of gas injection were evaluated.

Keywords: Tundish; Gas injection; Physical modeling; Inclusion.

1 Engenheiro Metalurgista, CQE/ASQ, Estudante do PPGEM, UFMG, Belo Horizonte, Minas Gerais, Brasil.

2 Estudantes de Engenharia Metalúrgica, UFMG, Belo Horizonte, Minas Gerais, Brasil.

Engenheiro Metalurgista, PhD, Professor, Departamento de Engenharia Metalúrgica, UFMG, Membro da ABM, Belo Horizonte, Minas Gerais, Brasil.

\footnotetext{
* Contribuição técnica ao 450 Seminário de Aciaria - Internacional, 25 a 28 de maio de 2014,
} 


\section{INTRODUÇÃO}

Em uma aciaria existem três etapas principais: refino primário, refino secundário (ou metalurgia de panela) e o lingotamento contínuo. As etapas de refinos são responsáveis pelo acerto de composição química, limpidez e ajuste de temperatura dos aços para o lingotamento. Esse último, por sua vez é responsável pela solidificação do aço líquido de forma controlada, o que assegura o atendimento da qualidade interna e superficial do aço sólido.

Numa condição ideal é desejável que o aço líquido, após o refino, apresente um nível de inclusões que não comprometa a sua lingotabilidade e principalmente a qualidade interna e superficial do produto no final da linha de laminação ou trefilação. Inúmeras técnicas são aplicadas para esse controle no refino secundário em uma aciaria, como o controle das características físico-químicas das escórias e a flotação de inclusões através da injeção de gás inerte por plugues porosos ou lanças.

Uma vez que existem vários fatores que originam as inclusões, reduzindo assim a qualidade do aço produzido, redundâncias ou reforços para a melhoria de sua qualidade são requeridos. Dessa forma, o distribuidor é projetado para cumprir esse papel, além das funções básicas de reservatório e distribuição do aço líquido.

Para maximizar a oportunidade de flotação de inclusões em um distribuidor, é conveniente inserir modificadores de fluxo em seu interior. Em geral esses modificadores são estruturas sólidas que atuam como obstáculos físicos e alteram o padrão de escoamento, agregando ao aço melhor resultado de qualidade. Além dos modificadores de fluxo tradicionais, o uso de cortina de gás [1] pode também desempenhar papel similar e favorecer de forma mais intensa a flotação de inclusões.

Para avaliar o efeito da injeção de gás no escoamento desse reator, é interessante determinar a curva de distribuição de tempos de residência, DTR [2], para cada configuração de interesse empregando modelos físicos a frio ou modelos matemáticos. Nos modelos físicos, a água é utilizada para simular o aço líquido.

Através da curva DTR, obtida com a técnica de injeção de traçador iônico, é possível caracterizar os respectivos volumes de trabalho do distribuidor, entre eles os volumes pistonado, de mistura e morto, e evidenciar até situações indesejáveis como o curto-circuito.

$\mathrm{Na}$ indústria, a cortina de gás pode ser criada pela colocação de um elemento poroso na base do distribuidor que é alimentada pela injeção de um gás inerte, normalmente argônio. O gás argônio ao se desprender do elemento poroso cria uma série de bolhas de gás que irão subir até a superfície do aço líquido no distribuidor. Durante esse percurso de ascensão, as bolhas que colidirem com as partículas de inclusões não metálicas, poderão aderir a elas, conduzindo-as para a escória do distribuidor em um processo similar ao de flotação [3].

Em geral, a eficiência de remoção de inclusões é afetada por inúmeras variáveis, dentre elas destacam-se: posição e tamanho do elemento poroso, tamanho médio das bolhas, tamanho médio das inclusões, pressão e vazão de gás de operação e velocidade de escoamento no distribuidor [1].

Com base nos experimentos, é possível determinar o efeito do uso da cortina de gás na curva DTR, para cada configuração interna testada.

O presente trabalho visa, através da análise das curvas DTR's e de imagens, elucidar as mudanças geradas no sistema, submetido à injeção de gás, assim como, determinar a melhor configuração, variando posição do plugue e vazão de gás.

* Contribuição técnica ao $45^{\circ}$ Seminário de Aciaria - Internacional, 25 a 28 de maio de 2014, Porto Alegre, RS, Brasil. 


\section{METODOLOGIA}

\subsection{Aparato Experimental}

Para realização dos experimentos, foram utilizados os recursos do Laboratório de Simulações de Processos - LaSiP, do Departamento de Engenharia Metalúrgica e de Materiais da Universidade Federal de Minas Gerais.

O modelamento físico é uma ferramenta na análise de escoamento para reatores metalúrgicos. Em um modelo de distribuidor construído em escala reduzida 1:3 de um distribuidor real em operação, que possui uma válvula de entrada e duas de saída, onde são respeitados aspectos de similaridade [4] geométrica e dinâmica, é factível fazer inferências do comportamento do escoamento pela aplicação de técnicas específicas e replicar o resultado para o ambiente industrial, o que elimina a necessidade de fazer testes diretamente na planta. A transposição do modelo de físico para o industrial, e vice-versa, pode ser feita através do critério de similaridade baseado no número de Froude.

A geometria e dimensões do distribuidor que serviu de base para o presente estudo podem ser vistas na Figura 1.
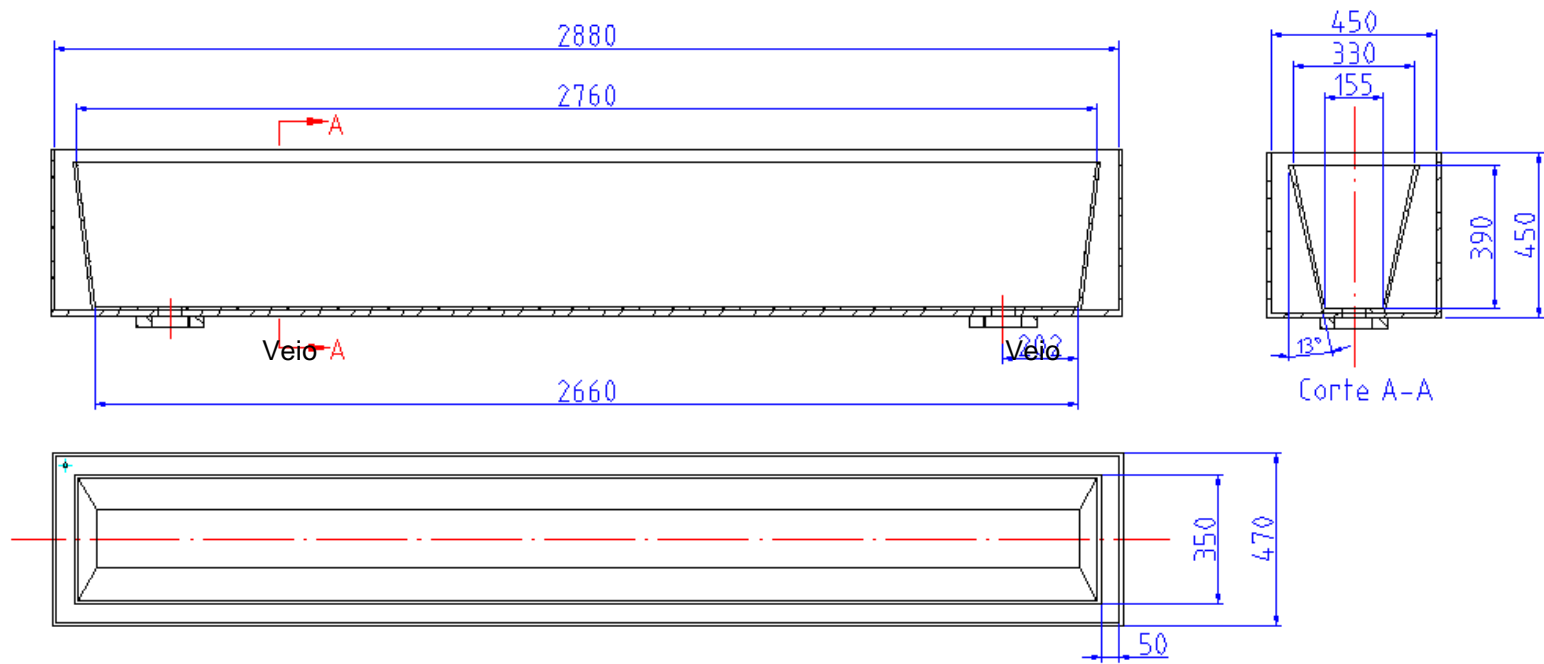

Figura 1. Desenho técnico do modelo do distribuidor (dimensões em mm).

\subsection{Determinação das Curvas DTR}

Para a realização dos testes relativos à obtenção das curvas DTR's, dois sensores de condutividade elétrica foram conectados aos veios de saída, inicialmente fechados, e o distribuidor foi preenchido com um volume de 167 litros de água atendendo os critérios de similaridade (correspondendo a 40 toneladas de aço no distribuidor). Depois de estabelecido o nível de operação, os veios foram abertos, permitindo que a soma das vazões de saída fosse a mesma de entrada, mantendo assim um estado estacionário. Para a injeção de gás, dois plugues porosos foram instalados simetricamente na base do distribuidor em relação aos veios de saída. A Figura 2 ilustra um plugue usado. Diferentes posições dos plugues e vazões, na faixa de 1,0 a 4,0 l/min, foram estudadas através de testes feitos em triplicata. Foram testadas três posições, sendo elas, $28 \mathrm{~cm}, 56 \mathrm{~cm}$ e $84 \mathrm{~cm}$ do veio de saída. A vazão de água na entrada do distribuidor foi mantida em $50 \mathrm{l} / \mathrm{min}$. Essa vazão corresponde ao lingotamento de dois veios de placas com $1,50 \mathrm{~m}$ de largura, 0,25 $\mathrm{m}$ de espessura a uma velocidade de 1,00 $\mathrm{m} / \mathrm{min}$.

* Contribuição técnica ao $45^{\circ}$ Seminário de Aciaria - Internacional, 25 a 28 de maio de 2014, Porto Alegre, RS, Brasil. 

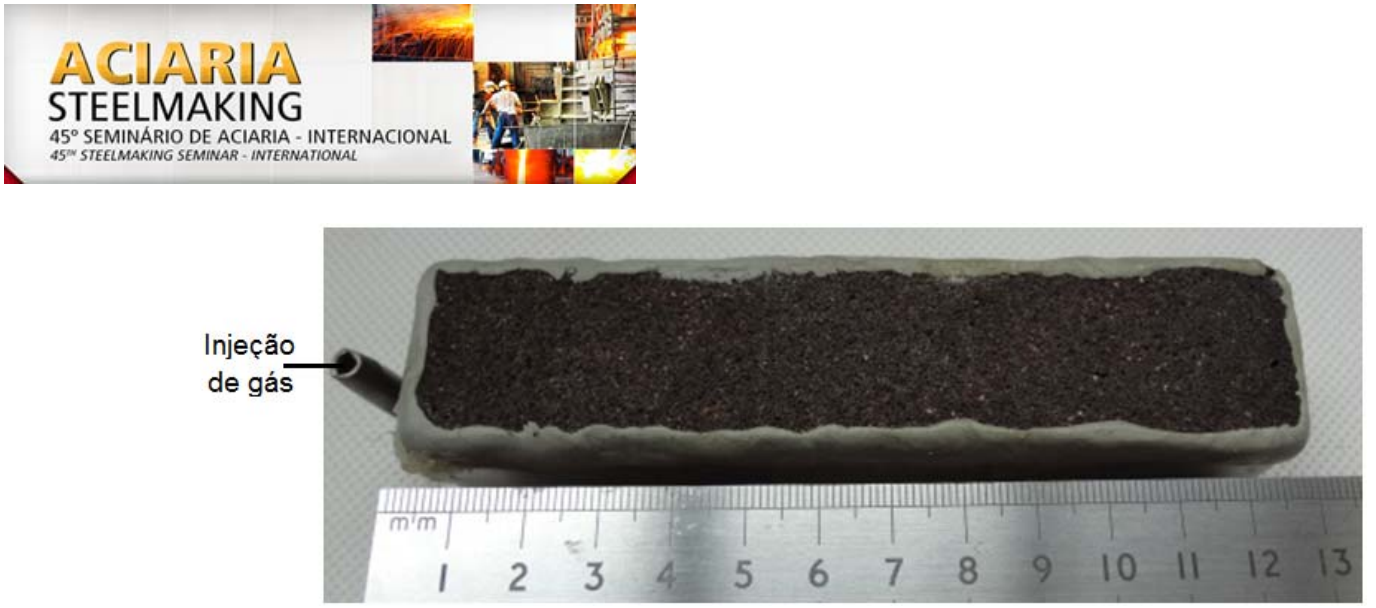

Figura 2. Elemento poroso utilizado.

A cortina de gás teve sua origem nesses elementos porosos de dimensões controladas, alimentados por gás, nesse caso por ar atmosférico comprimido. A vazão de ar comprimido foi controlada por rotâmetros e a pressão da linha por um manômetro.

Após se alcançar a altura padrão de água no distribuidor e o escoamento entrar em regime estacionário, foi feita a injeção de um traçador iônico, no caso o cloreto de potássio, na forma de um pulso com duração inferior a 2 segundos. Esse traçador altera a condutividade elétrica da água, fazendo com que os sensores de condutividade detectem essa variação em função do tempo, que mais tarde será transformada em concentração através do uso de uma curva de calibração levantada. O tratamento dos dados de variação de condutividade em função do tempo permite a determinação das curvas DTR's. Em geral, o tempo de aquisição de dados durou o equivalente a 4 tempos de residência teóricos do distribuidor.

Durante todo o ensaio, os condutivímetros permaneceram conectados a um computador, onde foram armazenados os dados experimentais.

Com base nos parâmetros do distribuidor, como tempo de residência teórico, $t_{R}$, $e$ concentração média de traçador, $\mathrm{C}_{\mathrm{m}}$, os dados de concentração de traçador nas saídas e o tempo foram adimensionalizados, gerando uma curva DTR, semelhante à mostrada na Figura 3.

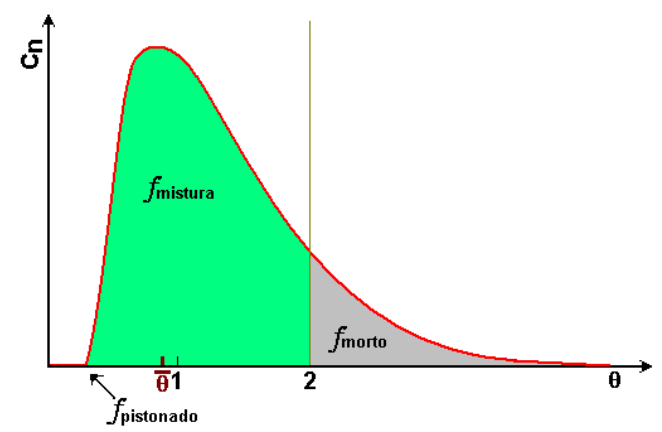

Figura 3. Parâmetros de uma curva DTR.

O tratamento da curva permite determinar parâmetros para caracterizar o comportamento de escoamento no distribuidor, conforme método proposto por Sahai [5]:

- Tempo de residência médio: indica o tempo médio, até duas vezes o tempo de residência teórico, que os elementos de volume ficaram no interior do reator;

- Fração de volume pistonado: esse parâmetro é obtido diretamente da curva DTR e refere-se ao tempo, após a injeção do traçador, durante o qual os sensores ficam sem estimulo da variação da concentração no meio, conforme seta indicativa na Figura 3;

* Contribuição técnica ao 45 Seminário de Aciaria - Internacional, 25 a 28 de maio de 2014, 
- Fração de volume morto: antes de calcular a fração de volume morto, é necessário calcular a integral da curva DTR até duas vezes o tempo de residência teórico.

De posse dos valores das frações de volume pistonado e morto, calcula-se o valor da fração de volume de mistura através da Equação 1:

$$
f_{\text {mistura }}=1-f_{\text {pistonado }}-f_{\text {morto }}
$$

Todos esses parâmetros podem ser vistos graficamente na Figura 3 .

A técnica de colorimetria, através da adição de corantes à água, como o permanganato de potássio, permite visualizar o escoamento, e por consequência, o caminho do traçador iônico, que aliado às filmagens dessa técnica, mostrou-se também uma ferramenta importante de análise do escoamento empregada nesse trabalho, pois possibilitou o entendimento do padrão de escoamento de uma forma geral.

Testes com injeção de partículas que simulam inclusões não metálicas, também foram feitos para posterior análise de imagens. As partículas utilizadas foram de borossilicato e foram injetadas através de uma bomba peristáltica. A concentração de partículas na polpa foi de $5 \mathrm{~g} / \mathrm{l}$ e vazão de injeção da polpa foi de $200 \mathrm{ml} / \mathrm{min}$.

\section{RESULTADOS E DISCUSSÃO}

\subsection{Curvas DTR's}

A fim de determinar o efeito da posição do plugue poroso, três diferentes posições, a diferentes distâncias da válvula longa, foram testadas. A intensidade da cortina de gás também foi um fator estudado e, para tal, foram testadas quatro vazões de gás utilizadas em cada posição. Para permitir a comparação com o funcionamento do distribuidor sem modificadores de fluxo, testes mantendo a configuração original do reator também foram feitos.

A partir dos dados obtidos nos testes e seu posterior tratamento, foram determinadas as curvas DTR's para cada configuração. As Figuras 4 a 8 contém a média das curvas dos dois veios de saída obtidas através dos testes realizados em triplicata, em cada posição para as diferentes vazões de gás.

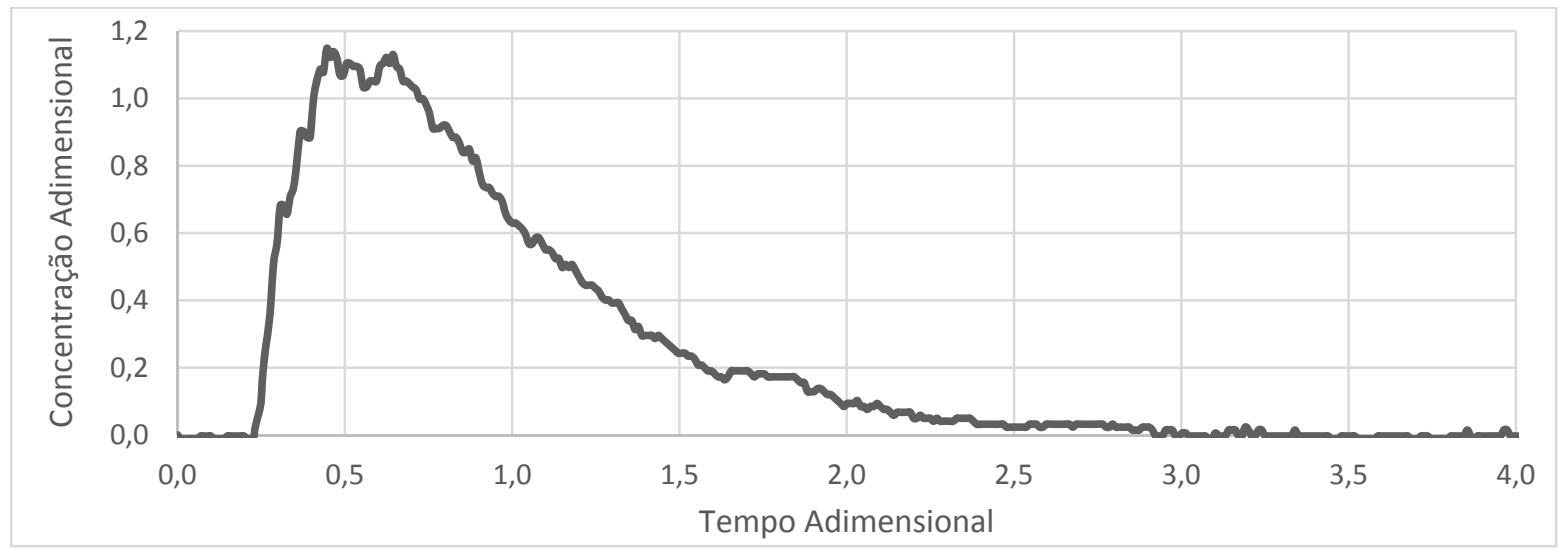

Figura 4. Curva DTR para o distribuidor sem injeção de gás.

* Contribuição técnica ao 450 Seminário de Aciaria - Internacional, 25 a 28 de maio de 2014, Porto Alegre, RS, Brasil. 
ACJÁlít

STEELMAKING

EE ACIARIA - INTERNACIONAL

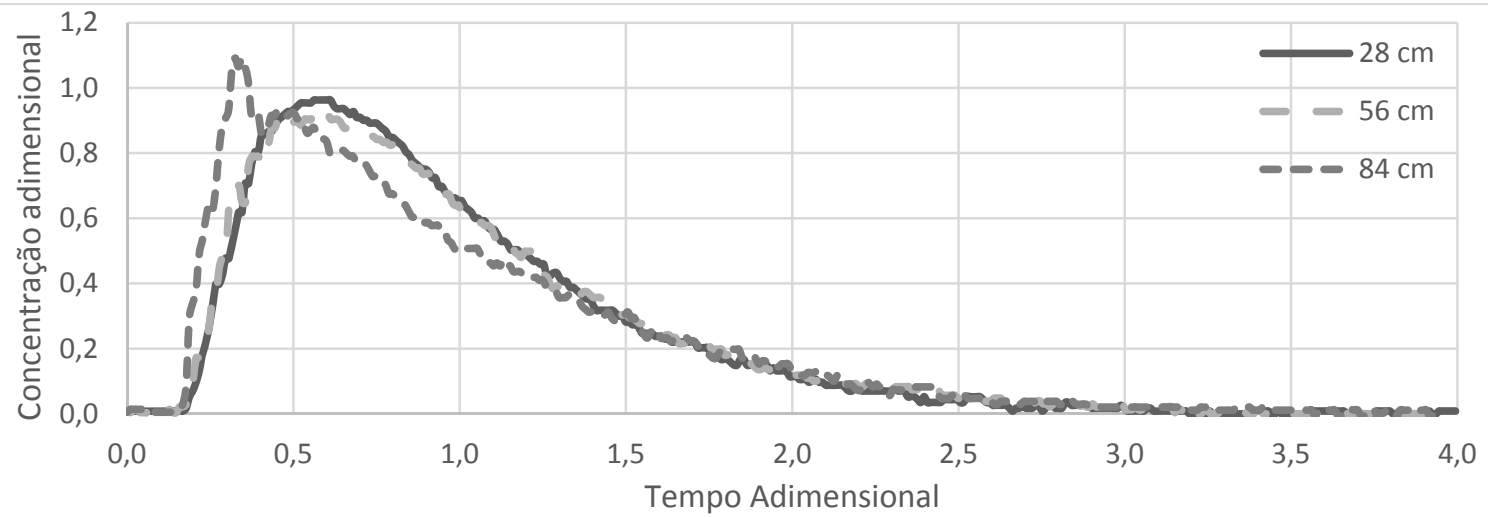

Figura 5. Curva DTR para distribuidor com cortina de gás com vazão de 1,0l/min.

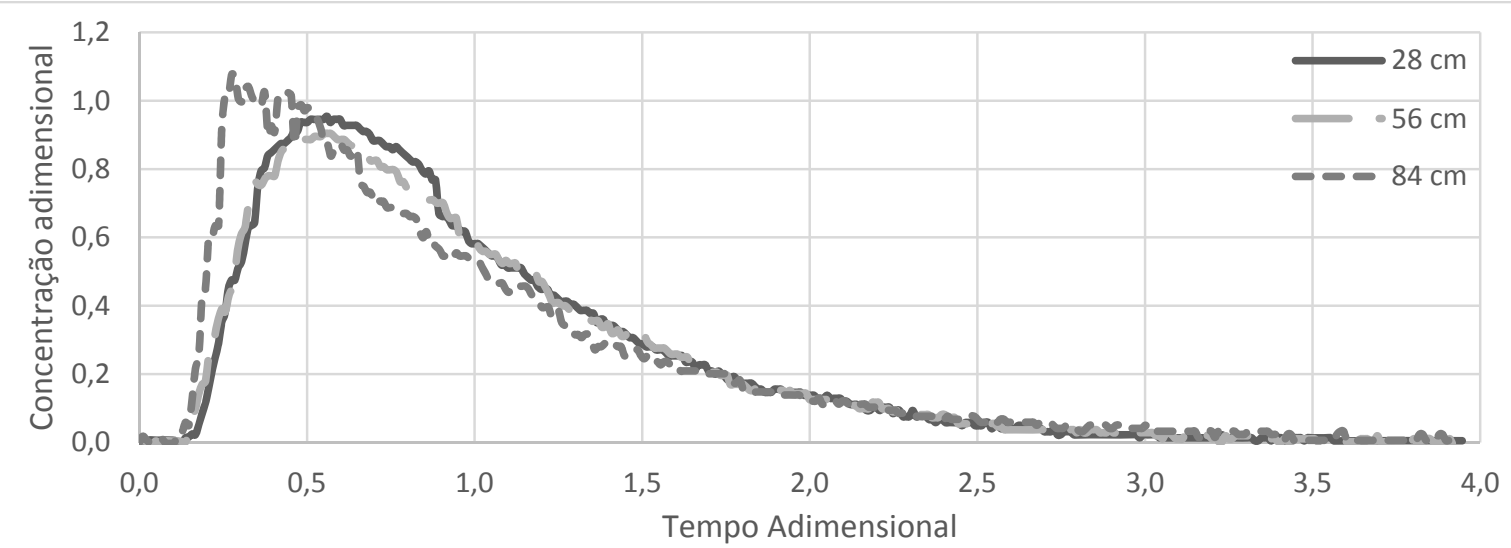

Figura 6. Curva DTR para distribuidor com cortina de gás com vazão de 2,0 l/min.

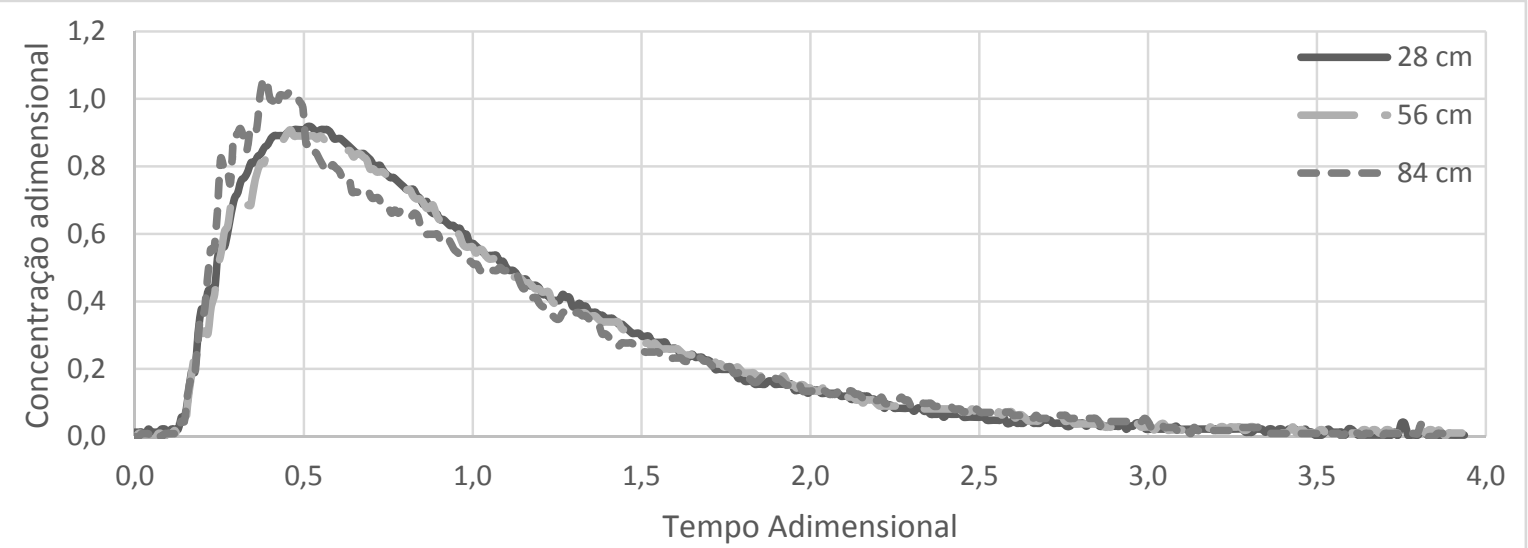

Figura 7. Curva DTR para distribuidor com cortina de gás com vazão de 3,0 l/min.

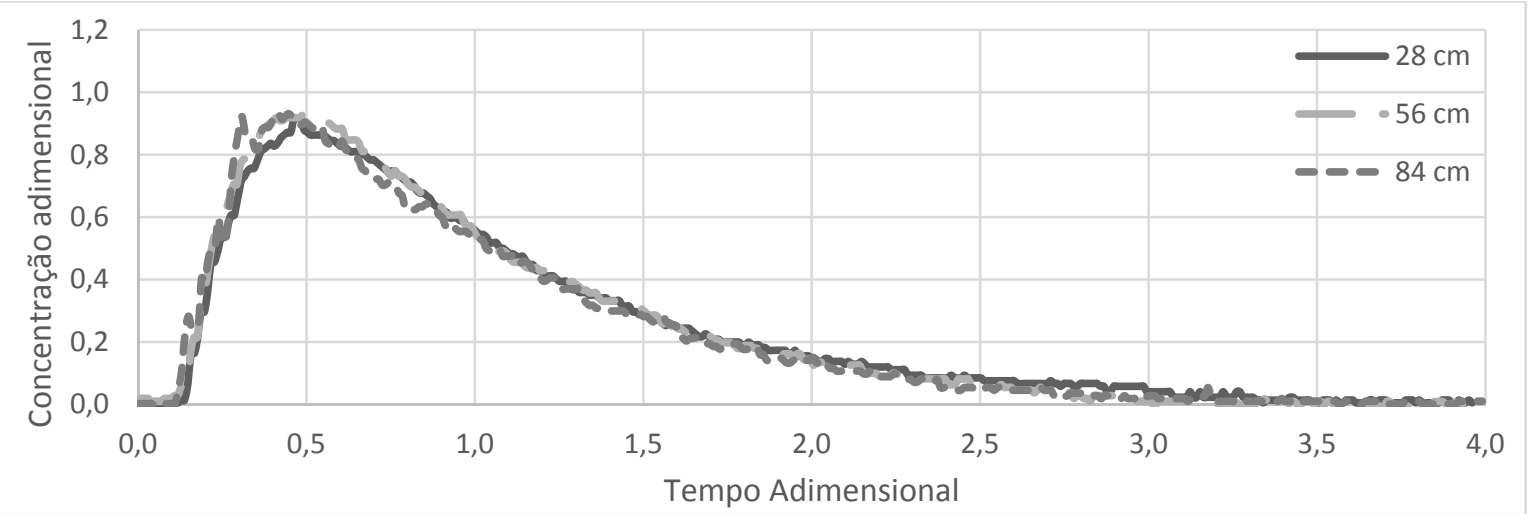

Figura 8. Curva DTR para distribuidor com cortina de gás com vazão de 4,0 l/min.

* Contribuição técnica ao 450 Seminário de Aciaria - Internacional, 25 a 28 de maio de 2014, Porto Alegre, RS, Brasil. 
A análise das curvas DTR's permite calcular, usando o método proposto por Sahai [5], as frações de volume pistonado, morto e de mistura no distribuidor. As frações de volume pistonado e morto foram obtidas para cada configuração estudada e estão apresentadas nas Figuras 9 e 10, respectivamente, por meio de gráficos boxplots. Os resultados estão agrupados em função das posições 28, 56 e $84 \mathrm{~cm}$ de afastamento do veio, e aumento gradativo de vazão de gás, obedecendo a sequência de 1,0; 2,0; 3,0 e 4,0 I/min registrada entre parênteses nas figuras citadas e a respectiva média de cada boxplot.

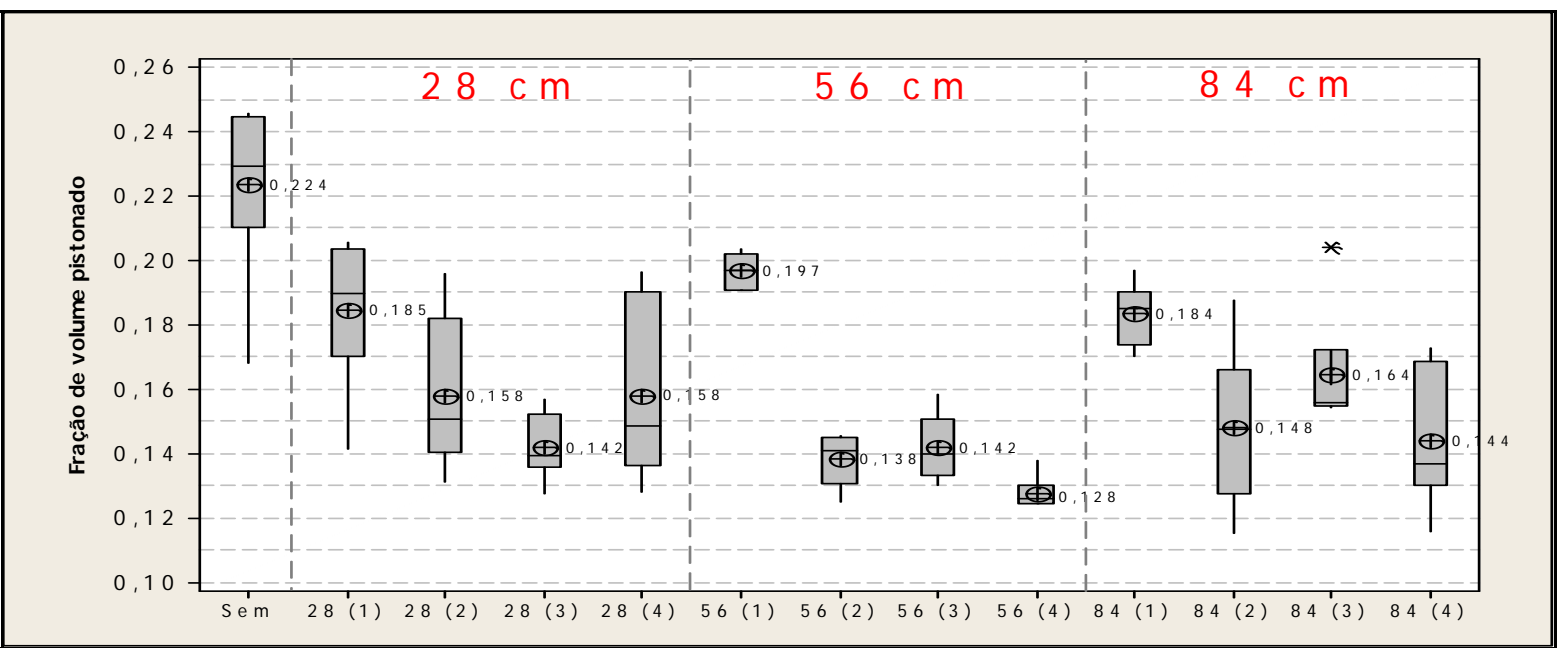

Figura 9. Comportamento do volume pistonado sem e com cortina de gás, variando posição e vazão de gás. Notação: Posição em cm e vazão de gás em l/min entre parênteses.

Na Figura 9 observa-se que a maior fração de volume pistonado está associada à configuração sem a cortina de gás, conforme o boxplot mais à esquerda. Indiferente da posição da cortina em relação à saída do veio, à medida que a vazão de gás aumenta, o volume pistonado tende a reduzir. Uma hipótese levantada é que o deslocamento da massa de fluido pela cortina de gás gera uma velocidade maior na região da superfície do distribuidor em direção ao veio, reduzindo o volume pistonado. Quanto maior for a vazão de gás da cortina, maior será esse efeito da redução do volume pistonado, contudo, segundo a literatura, para flotação de inclusões, o ideal é o maior volume pistonado.

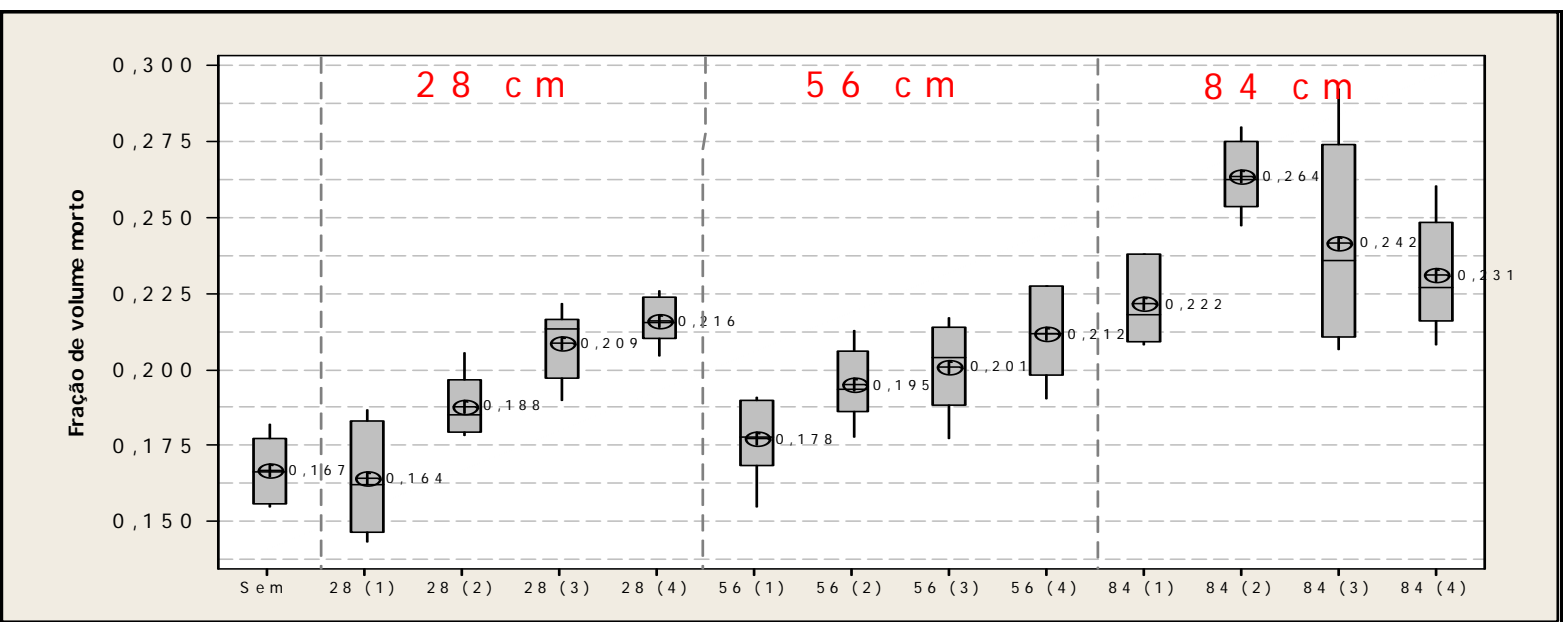

Figura 10. Comportamento do volume morto sem e com cortina de gás, variando posição e vazão de gás. Notação: Posição em cm e vazão de gás em I/min entre parênteses.

* Contribuição técnica ao 450 Seminário de Aciaria - Internacional, 25 a 28 de maio de 2014, Porto Alegre, RS, Brasil. 
Conforme Figura 10, para as posições de 28 e $56 \mathrm{~cm}$ de afastamento do veio, à medida que a vazão de argônio aumenta, a fração de volume morto tende a crescer. Isso pode ser explicado em função da formação de um volume central, de baixa velocidade. O fluido que é lançado para cima, cria uma grande renovação do aço na superfície do distribuidor e testes de colorimetria elucidam esse mecanismo. A cortina com maior afastamento da saída do distribuidor apresentou a maior fração de volume morto, sendo que a vazão de gás teve pequeno efeito. Acredita-se que, como a distância é maior, o efeito da região morta se intensificou e estabilizou.

\subsection{Análise de Imagens}

A sequência de imagens retratadas na Figura 11 baseia-se no método de colorimetria, onde o avanço da frente de injeção de permanganato de potássio elucida alguns pontos anteriormente explanados. A primeira coluna faz referência ao tempo do quadro mostrado, em relação ao instante da injeção do corante. A segunda coluna faz referência a um pulso de corante no distribuidor sem cortina de gás e a terceira coluna, a um pulso similar, mas com o uso da cortina na posição 56 $\mathrm{cm}$ e vazão de gás de 4,0 I/min. As imagens da Figura 11 apresentam apenas o lado direito do modelo, uma vez que o sistema é simétrico, e em sua parte de cima está posicionado um espelho a $45^{\circ}$ para detalhar o avanço da frente de corante pela vista superior. A seta para baixo localiza o local da injeção do corante e a seta para cima identifica a posição da injeção de gás. Nessas Figuras, a metade superior mostra uma vista de cima do distribuidor e a metade inferior uma vista frontal.

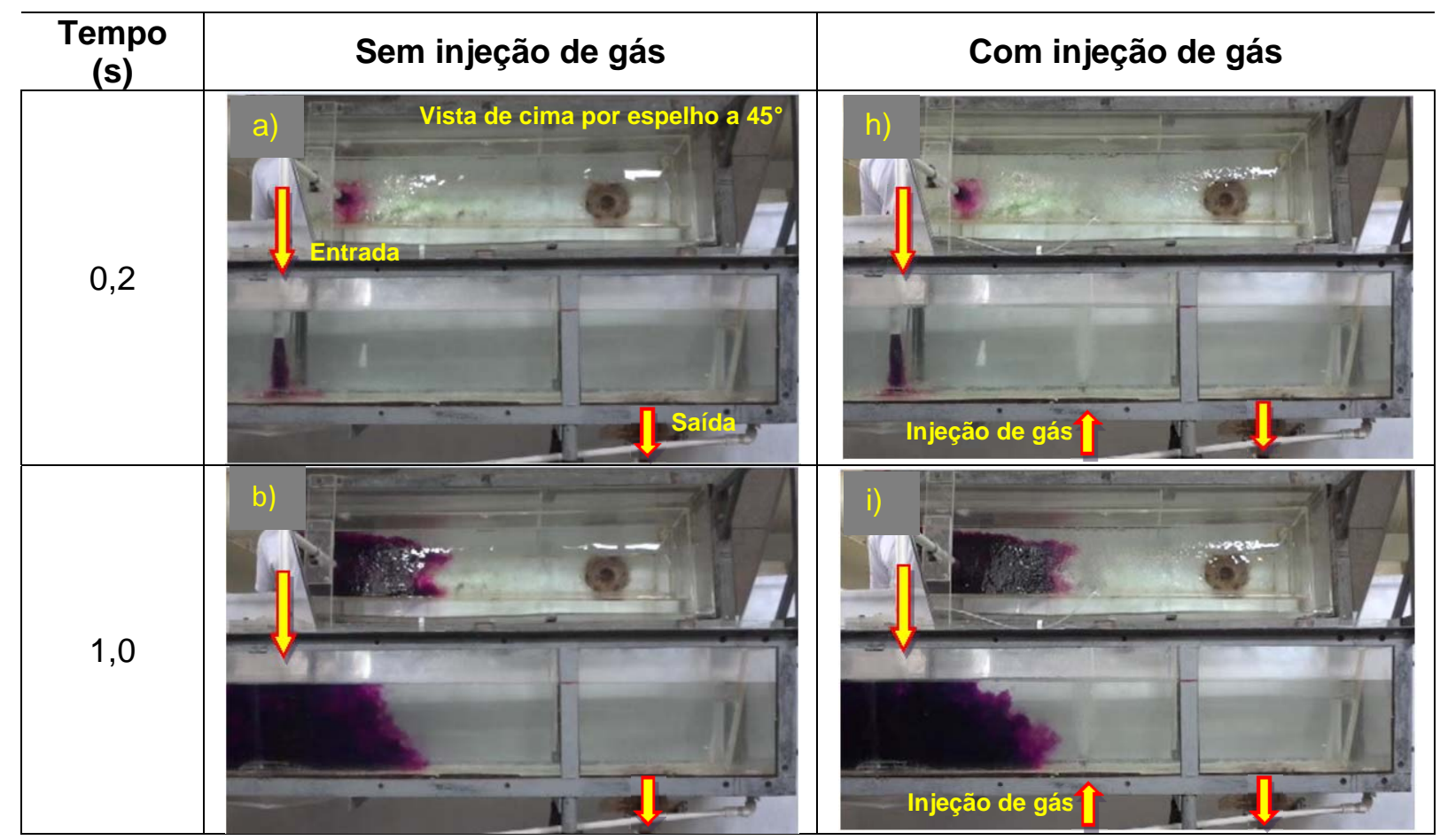

Figura 11. Sequência de imagens de injeção de corante sem (a-g) e com (h-o) cortina de gás.

* Contribuição técnica ao 45 Seminário de Aciaria - Internacional, 25 a 28 de maio de 2014, 


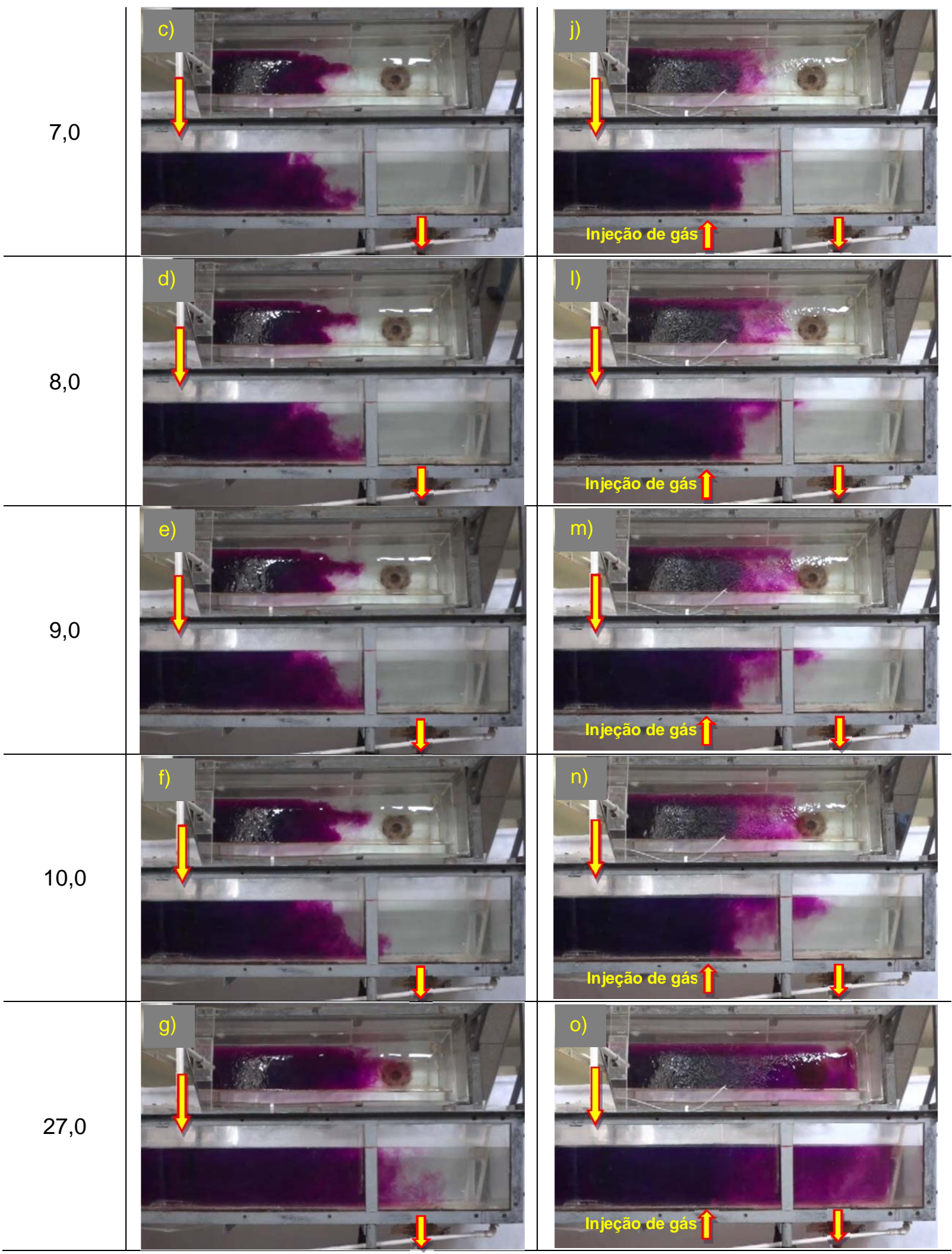

Figura 11. Sequência de imagens de injeção de corante sem (a-g) e com (h-o) cortina de gás (Cont.).

Pela sequência das Figuras $11 \mathrm{a}$ a $11 \mathrm{~g}$, nota-se que a frente de corante avança uniformemente na direção da saída do veio, sem apresentar nenhuma componente vertical de fluxo até próximo à saída do veio, quando o fluxo se torna descendente.

* Contribuição técnica ao $45^{\circ}$ Seminário de Aciaria - Internacional, 25 a 28 de maio de 2014, Porto Alegre, RS, Brasil. 


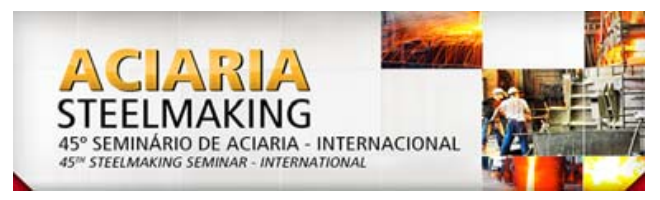

Para as imagens mostradas nas Figuras de $11 \mathrm{~h}$ a $11 \mathrm{i}$ constata-se um fluxo similar ao anterior, mas a velocidade do fluido já apresenta uma componente vertical, observada pela inclinação da interface corante-água até a região da cortina de gás. Após esse limite, o fluxo se torna ascendente, na Figura $11 \mathrm{j}$, tornando a componente vertical mais significativa. Pode-se observar que após a cortina existe a formação de uma região de mistura pouco intensa, o que evidencia a formação de uma região morta ou estagnada. Esse fato confirma a proposição anterior da análise do volume morto da Figura 10, relativo à posição mais afastada em relação ao veio para injeção de gás.

Embora a análise das DTR's não indique efeito positivo da injeção de gás, o escoamento ascendente criado pelo gás favorece a remoção de inclusões. Para verificar este fato, foi analisada a flotação de partículas de borosilicato, de maneira qualitativa. A Figura 12 ilustra essa análise que foi feita durante um teste de injeção de partículas utilizadas para simular inclusões. A vazão de gás durante o teste foi de $4,0 \mathrm{l} / \mathrm{min}$ e a posição do plugue foi a de $28 \mathrm{~cm}$ do veio. Esta imagem foi registrada após dois tempos de residência nominais, garantindo regime estacionário ao sistema.

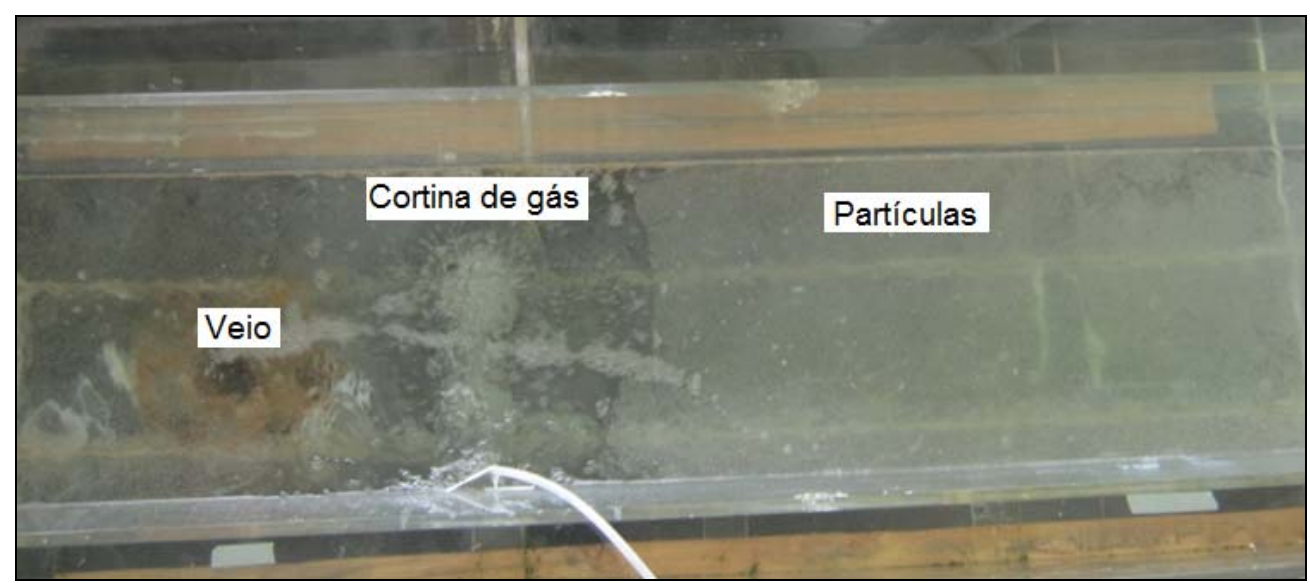

Figura 12. Imagem da vista superior do distribuidor durante teste de injeção de partículas de borosilicato.

Como pode ser percebido na Figura 12, a concentração de partículas na região anterior ao plugue poroso é maior em relação a região posterior. Tal fato pode ser verificado pela diferença de coloração, evidenciando, portanto, um perfil favorável à redução do número de partículas que eventualmente chegaria ao veio.

\subsection{Transposição dos Resultados para Escala Industrial}

Considerando o critério de similaridade baseado na igualdade do número de Froude, é possível transpor a vazão utilizada no modelo físico para a escala industrial seguindo as equações propostas por Mazumdar e Evans [6].

$$
\begin{gathered}
Q_{\text {ind }}\left(\frac{m^{3}}{s}\right)=Q_{\text {ind }}\left(\frac{N m^{3}}{s}\right) * \frac{1873}{273} * \frac{Q_{\text {mod }}=Q_{\text {ind }} * \gamma^{2,5}}{\left(1+\frac{\rho_{a c ̧ o} * g * H_{\text {ind }}}{2 * 101330}\right)} \\
Q_{\text {mod }}\left(\frac{m^{3}}{s}\right)=Q_{\text {mod }}\left(\frac{N m^{3}}{s}\right) * \frac{298}{273} * \frac{1}{\left(1+\frac{\rho_{\text {água }} * g * H_{\text {mod }}}{2 * 101330}\right)}
\end{gathered}
$$

* Contribuição técnica ao 450 Seminário de Aciaria - Internacional, 25 a 28 de maio de 2014, Porto Alegre, RS, Brasil. 
Nessas, $Q_{\text {ind }}$ representa a vazão de gás no distribuidor industrial, $Q_{m o d}$ a vazão de gás no modelo físico, $g$ é a aceleração da gravidade $\left(9,81 \mathrm{~m} / \mathrm{s}^{2}\right), H_{\text {mod }}$ a altura da coluna de água no modelo físico $(0,2765 \mathrm{~m}), H_{\text {ind }}$ a altura da coluna de aço no

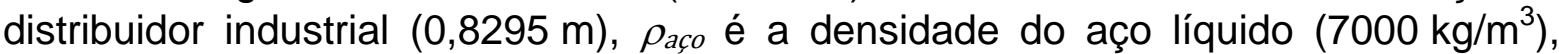

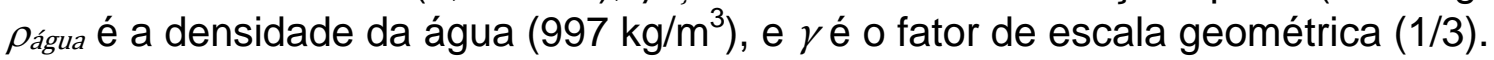

A partir dos valores de vazão de gás utilizados nos experimentos, e utilizando as equações citadas, são obtidos os valores de vazão correspondentes à escala industrial, conforme mostrado na Tabela 1.

Tabela 1. Transposição das vazões do modelo físico para a condição industrial

\begin{tabular}{c|c}
$\begin{array}{c}\text { Vazão de gás no modelo físico } \\
(\mathbf{l} / \mathbf{m i n})\end{array}$ & $\begin{array}{c}\text { Vazão de gás no distribuidor industrial } \\
\text { (NI/min) }\end{array}$ \\
\hline 1,0 & 3,14 \\
\hline 2,0 & 6,27 \\
\hline 3,0 & 9,41 \\
\hline 4,0 & 12,54 \\
\hline
\end{tabular}

\section{CONCLUSÕES}

A injeção de gás no distribuidor modificou a curva DTR em relação à configuração sem injeção de gás. Com isso, suas respectivas frações volumétricas alteraram-se, a saber:

- O volume pistonado apresentou tendência de redução em relação à condição de referência, sem injeção de gás. À medida que a vazão de gás injetada aumenta, essa redução se torna mais intensa;

- O volume de mistura, para as duas posições mais próximas da saída, apresentou um aumento médio em relação à condição original sem injeção de gás, fato esse que tem potencial para favorecer o coalescimento das partículas e sua flotação;

- O volume morto apresentou uma tendência de crescimento para as duas posições de injeção de gás mais próximas da válvula de entrada, à medida que a vazão de argônio aumenta;

- Pela técnica de colorimetria é possível notar que, na injeção de gás, existe um fluxo de escoamento ascendente próximo à camada da cortina gasosa, que a acelera e faz com que o volume deslocado chegue mais rápido na saída do veio, razão pela qual ocorre a redução do volume pistonado. Também foi identificada uma região com velocidades baixas, que justifica o aumento da fração de volume morto. Quanto maior a vazão de gás injetada, mais nítidas essas observações se mostram;

- A análise das curvas DTR's isoladamente não é muito representativa para avaliar a remoção de inclusões através da injeção de gás. As curvas devem ser analisadas juntamente com outros fatores considerados mais significativos, como o uso da técnica de colorimetria e o uso de partículas que simulem as inclusões não metálicas. Através desta última técnica, evidenciou-se o efeito positivo da cortina de gás na remoção de inclusões.

\section{Agradecimentos}

Os autores agradecem a FAPEMIG pelo apoio financeiro concedido ao projeto Processo TEC - APQ-00373-11 - "Modelamento Físico E Matemático Do Escoamento Multifásico Em Sistemas Metalúrgicos".

* Contribuição técnica ao 450 Seminário de Aciaria - Internacional, 25 a 28 de maio de 2014, Porto Alegre, RS, Brasil. 
Os autores agradecem também o apoio da CAPES/PROEX ao programa de pósgraduação PPGEM/UFMG.

\section{REFERÊNCIAS}

1 Nascimento RP. Remoção de inclusões não-metálicas do aço líquido através do borbulhamento de argônio pelo fundo do distribuidor de lingotamento contínuo da ArcelorMittal Tubarão [dissertação de mestrado]. Ouro Preto: Programa de Pósgraduação em Engenharia de Materiais da REDEMAT da Escola de Engenharia da UFOP; 2008. p.55-69.

2 Costa AMC. Modelamento matemático da zona de mistura no lingotamento contínuo [dissertação de mestrado]. Belo Horizonte: Curso de Pós-graduação em Engenharia Metalúrgica e de Minas da Escola de Engenharia da UFMG; 2003. p.4-52.

3 Miki Y, Takeuchi S. Internal defects of continuous casting slabs caused by assimetric unbalanced steel flow in molde. ISIJ International; 2003;43(10):1548-55.

4 Wollmann AM. Estudo de fluxo em um distribuidor de lingotamento contínuo[dissertação de mestrado]. Porto Alegre: Programa de Pós-graduação em Engenharia Metalúrgica, Minas e Materiais da Escola de Engenharia da UFRGS; 1999. p.8-29.

5 Sahai $Y$, Emi T. Melt flow characterization in continuous casting tundishes. ISIJ International. 1996;36(6):667-672.

6 Mazumdar D, Evans JW. Modeling of Steelmaking Processes. CRC Press; 2009. p.119.

* Contribuição técnica ao 45 Seminário de Aciaria - Internacional, 25 a 28 de maio de 2014, Porto Alegre, RS, Brasil. 